Journal of

Dentistry and Oral Health

\title{
Evaluation of Antibacterial Properties of Resin Composites Containing Silver Nanoparticles on Streptococcus Mutans
}

\author{
A Farahani ${ }^{1}$, A Beyrami ${ }^{2}$, H Piri ${ }^{3}$, A Naghizadeh ${ }^{4}$, H Imani $^{5}$, MH Farahani ${ }^{* *}$ \\ ${ }^{1}$ Student Research Committee, Faculty of Dentistry, Arak University of Medical Science, Arak, Iran \\ ${ }^{2}$ Assistant Professor, Department of Pediatric Dentistry, faculty of Dentistry, Ardabil University of Medical Sciences, \\ Ardabil, Iran \\ ${ }^{3}$ Associate Professor, Department of Microbiology, Faculty of Medicine, Ardabil University of Medical Sciences, \\ Ardabil, Iran \\ ${ }^{4}$ Associate Professor, Department of Physical Education, Faculty of Medicine, Ardabil University of Medical Science, \\ Ardabil, Iran \\ ${ }^{5}$ Student Research Committee, Faculty of Medicine, Ardabil University of Medical Science, Ardabil, Iran \\ ${ }^{6}$ Student Research Committee, Faculty of Dentistry, Shahid Beheshti University of Medical Science, Tehran, Iran
}

*Corresponding author: Mohammad Hossein Farahani, Department of orthodontics, Faculty of dentistry, Shahid Beheshti University of medical science, Tehran. TEL: +989144500840; E-mail: mohammadfarahani2009@gmail.com

Received Date: August 22, 2018; Accepted Date: September 29, 2018; Published Date: October 08, 2018

Citation: A Farahani (2018) Evaluation of Antibacterial Properties of Resin Composites Containing Silver Nanoparticles on Streptococcus Mutans. J Dent Oral Health 5: 1-6.

\begin{abstract}
Background and Objectives: Studies showed that resin composites are more susceptible to aggregation of biofilm than amalgam and glass ionomers and have lesser antibacterial effects which results in increasing the rate of secondary caries? Therefore, production of antibacterial resin composites was always under investigation. Thus, the aim of this study is evaluating the efficacy of resin composites containing silver nanoparticles against the Streptococcus Mutans.

Methods: In this experimental study, the antibacterial properties of resin composites incorporating 0, 0/02, 0/03, 0/04, 0/05\% w/w of Nano silver particles was investigated using turbidity test. Composites was formed on the walls of $400 \mathrm{ml}$ micro plates and after the curing, they left in contact with bacterial suspension. In times of 3, 24 and 48 hours, the optical density of the broth was read by spectrophotometer. The data was analyzed by Kolmogorov-Smirnov, one-way ANOVA, LSD test and repeated measure ANOVA.
\end{abstract}

Results: The results showed that all composites containing silver nanoparticles had antibacterial effects ( $p \leq 0 / 05)$ and by increasing the amount of silver nanoparticles to $0 / 03 \% \mathrm{w} / \mathrm{w}$, the anti-bactericidal effect rose and the bacterial growth significantly diminished $(\mathrm{p}=0 / 001)$. However, in higher concentrations than $0 / 03 \%$, this effect decreased. The $\mathrm{MBC}$ (minimum bactericidal concentration) were seen in composites with $0 / 02$ percent of silver nanoparticles.

Conclusion: While all composite groups containing silver nanoparticles had antibacterial effect, the most efficient group was $0 / 03 \% \mathrm{w} / \mathrm{w}$ and by increasing the amount of silver nanoparticles over $0 / 04 \%$, the antibacterial effect didn't increase significantly.

Keywords: Silver nanoparticles; Streptococcus mutans; Resin composites 


\section{Introduction}

Dental caries has become a common oral health problem in many countries including developed nations. Inappropriate oral and dental hygiene causes anaerobic bacterial growth, and proliferation of plaque and dental calculus [1]. Dental caries is caused by prolonged episodes of low $\mathrm{PH}$ resulting from acid production of bacterial biofilm. These biofilms are formed by bacteria such as Streptococcus mutans, which adhere to the tooth surfaces, producing organic acid metabolites that lead to demineralization of enamel [2]. Secondary caries is a lesion that occurs on a tooth, at the edge of a restored lesion, frequently known as the most common cause of restoration replacement, regardless of the type of restorative material $[3,4]$ Generally, secondary or recurrent caries is defined as a primary carious lesion at the margin of an existing restoration that has been used for a while. The biofilms have shown different adhesion strengths with different restorative materials [5]. Studies show that composite resins have a tendency of higher accumulation of biofilms and lower antibacterial effects than amalgams and glass ionomers, which in turn increases the rate of secondary caries [6]. Therefore, to prevent secondary caries, it is of utmost importance to repair and prevent the growth of biofilms on tooth surfaces [7]. Since oral hygiene and the durability of restorations is important, much research has been conducted to create antibacterial effects in composite resins by adding compounds such as titanium, gold, and silver particles [8,9]. The effect of silver as an antibacterial agent has been known for many years [10]. Silver nanoparticles not only affect gram-negative bacteria and gram-positive bacteria, but also influence a wide spectrum of antibiotic-resistant microbes. The antibacterial effect depends on the particle size and concentration; so, the greater the concentration and the smaller the particles, the more effective will be its cytotoxic properties [11]. Apart from the size and concentration, the particle shape is also important. Based on research, nanoplates have been found to be more effective than other particle forms [12]. These particles tend to have molecular groups containing phosphorus and sulfur. The silver nanoparticles penetrate the bacterial cell wall, releasing silver ions that bind bacteria's DNA and subsequently disrupt the electron transfer chain of the bacteria [7]. According to studies, fillers containing silver particles exhibited high antibacterial defense against Streptococcus mutans [13]. In the present study, we have investigated the antibacterial properties and the minimum concentration of nanoparticles required in composite resin for efficacy against Streptococcus mutans, by adding different weight percentages of silver nanoparticles to composite resins.

\section{Materials and Methods}

This is a laboratory study, wherein the study population consisted of five groups of flowable resin composites (3M, ESPE@, USA), containing zero, two-, three-, four-, and fivehundredths by weight of silver nanoparticles (NANOSAV, IRAN), respectively, with an average particle size of $40 \mathrm{~nm}$ in direct contact with Streptococcus mutans (Streptococcus mutans PTCC 1683, IROST $\odot$, Tehran). In the first stage, the groups to be studied were prepared by weighing the silver nanoparticles on digital scale (Sartorius CAP 225, Cubis@), Germany) and then adding these, in the specified percentages, to the resin composites. The reactions were conducted in a special darkroom, under red protective lighting ( $15 \mathrm{w}$, Imaging warehouse, UK), stirring for 20 minutes with a plastic spatula. Since the direct contact test required floating bacteria in the liquid medium to be in contact with the resin material, sterile 96-well microplates (Biooff( $)$, Iran) with a capacity of $400 \mu \mathrm{L}$ volume, were selected to prevent possible contamination of the culture medium. Based on the bacterial culture duration, a total of 90 microplates were prepared. Then, using an insulin syringe, $100 \mu \mathrm{L}$ of each composite material group was introduced into the wells, and the degree of polymerization shrinkage of composite was reduced using a light-curing instrument (Ultradent $@$ - VALO.USA). Thus, a certain volume of the wells was occupied by the composite materials (100 $\mu \mathrm{L}$ ) and the remaining $300 \mu \mathrm{L}$ volume was subsequently filled with the liquid culture, where the said culture in contact with the composite was tested. In this experiment, six samples were prepared from each group and 90 microplates were prepared according to the time of culture of the bacteria. The spectrophotometric (synergy HT, BioTek ${ }^{\varpi}$ ) test was performed to study antibacterial properties at the surface of composites containing silver nanoparticles. First, the bacteria were cultured on a solid culture medium (sigmaaldrich $\odot$ ). The cultivated colonies were then used to prepare suspensions required as the McFarland standard solution as well as serial dilutions. The entire process is based on the CLSI 2015 guidelines. A standard half-McFarland solution of $10 \mu \mathrm{L}$ was poured into each dish along with $150 \mu \mathrm{L}$ of Tryptic soy broth (TSB, Merck@), Germany). The dishes were sealed and kept Incubated (EMS MyTemp ${ }^{\mathrm{Tm}} 65 \mathrm{HC}$ ) at $37^{\circ} \mathrm{C}$. After each time interval of 3, 24, and 48 hours, the optical density of the culture media was recorded by a spectrophotometer at a wavelength of $600 \mathrm{~nm}$. To determine the amount of bacteria, an optical density-specific bacterial counting chart was used to prepare a standard half-McFarland solution (containing $10.5^{\star} 10^{8}$ Streptococcus mutans per $\mathrm{mL}$ ) and the spectrophotometer 
device was adjusted to the wavelength of $600 \mathrm{~nm}$. The optical density was determined and its value recorded on the vertical axis of the graph. Then, using serial dilution, the optical densities were recorded for different bacterial counts, and a curve was plotted. By obtaining the linear regression equation, the number of Streptococcus mutans bacteria was determined. In addition, the optical density values up to a maximum of 0.3 were allowed and higher values were considered invalid.

\section{Statistical Analysis}

To determine the normal distribution of variables in each group, the Kolmogorov-Smirnov test was used. Further, to determine the difference in the mean optical density of composite wells containing different weight percentages of silver nanoparticles in the time periods of the measurement, repeated-measures ANOVA was used. To determine the difference between the mean optical density and the number of bacteria in the wells containing different percentages of silver nanoparticles at each time interval of 3, 24, and 48 hours, one-way ANOVA and post hoc test (LSD) were used. The level of significance was less than 0.05 .

\section{Results}

The mean and standard deviations of optical density and bacterial count are shown in Table 1 . The average number of bacteria and optical density of composite wells with different percentages of silver nanoparticles for different hours are shown in Tables 2 and 3. The comparison between the mean number of bacteria and different time durations at maximum value of $0.03 \%$ of silver nanoparticles with time, showed significant reduction of bacterial count, but at higher concentrations this difference was not significant.

\section{Discussion}

Due to its antimicrobial properties, the industrial and medical applications of silver nanoparticles are constantly increasing. Among restorative materials, composite resins are the best substances for surface absorption of microorganisms [14,15]. In this research, the effect of anti-mutant composite resin, supplemented with silver nanoparticles of values $0.02,0.03$, 0.04 , and $0.05 \%$, was investigated. The results show that composites containing silver nanoparticles, in contrast to nonnanoparticle composites, significantly restricted the growth of Streptococcus mutans in their vicinity, which is consistent with the results of all other studies. The antibacterial effect increased with an increase in the concentration of silver nanoparticles up to a value of $0.03 \%$, but in higher concentrations this effect then decreased. However, this is not consistent with the results of studies by Shafiei et al [4], Nam et al. [15], and Azarsina et al. [13], which show a direct relationship between increasing the concentration of silver nanoparticles and antibacterial effects. Meanwhile, the study by Patrícia Bolzan Agnelli das Neves et al. stated that an increase in concentration is not indicative of an increase in antibacterial activity as is suggested by our research, too [7]. In this study, direct contact was used to evaluate the antibacterial properties of composite resins. Nam et al. in their study showed that tissue regenerative material containing silver nanoparticles has a significant antibacterial effect in comparison with the control (with no nanoparticles), and this effect intensifies with the increase in the concentration of nanoparticles. Thus, while demonstrating the antibacterial properties of silver nanoparticles, they pointed to the unknown mechanism of the silver-containing compounds, and explained that it cannot be concluded that silver nanoparticles are released from the specimens, or that they show their antibacterial effect in direct contact with the microbial cells. They continued to emphasize that the function of silver as a catalyst turns oxygen into activated oxygen (including hydroxyl radicals), which is facilitated by light energy and/or $\mathrm{H} 2 \mathrm{O}$ in air or water at polar surfaces. As a result, these active oxygen radicals prevent the growth of bacteria. Sondi et al. [16] in their study, pointed to an unknown mechanism of inhibiting silver nanoparticles, and emphasized that when exposed to silver nanoparticles, cellular proteins are inactivated and microorganisms lose their ability to replicate. Patrícia Bolzan Agnelli das Neves et al. [7] added 0.3 and $0.6 \mathrm{wt} \%$ silver nanoparticles to resin composites in the laboratory. The microscopic analysis showed no difference in surface roughness between the two groups and the nonnanoparticle group. The antibacterial effect of the $0.3 \%$ group was more than the other group and, in general, more than the 


\begin{tabular}{|c|c|c|c|c|}
\hline p-value & Bacteria count & Optical density & Time (Hour) & $\begin{array}{l}\text { Silver nanoparticles } \\
\text { Concentration } \\
\text { (percent) }\end{array}$ \\
\hline \multirow[t]{3}{*}{$0 / 001$} & $9199166 \pm 21872 / 820$ & $0 / 089 \pm 0 / 0005$ & 3 & \multirow[t]{2}{*}{$0 / 00$} \\
\hline & $9787083 \pm 21872 / 420$ & $0 / 094 \pm 0 / 0005$ & 24 & \\
\hline & $1048750 \pm 37884 / 40$ & $0 / 101 \pm 0 / 0009$ & 48 & \multirow[t]{4}{*}{$0 / 02$} \\
\hline \multirow[t]{3}{*}{$0 / 73$} & $8300000 \pm 37884$ & $0 / 080 \pm 0 / 0009$ & 3 & \\
\hline & $8334583 \pm 87489$ & $0 / 080 \pm 0 / 0020$ & 24 & \\
\hline & $8334583 \pm 21872$ & $0 / 080 \pm 0 / 0005$ & 48 & \\
\hline \multirow[t]{3}{*}{$0 / 003$} & $8300000 \pm 92796$ & $0 / 080 \pm 0 / 0009$ & 3 & \multirow[t]{3}{*}{$0 / 03$} \\
\hline & $8127083 \pm 14149$ & $0 / 079 \pm 0 / 0013$ & 24 & \\
\hline & $8196250 \pm 92796$ & $0 / 079 \pm 0 / 0008$ & 48 & \\
\hline
\end{tabular}

Table 1. The mean and standard deviation of optical density and bacterial count

\begin{tabular}{|l|l|l|l|l|l|l|}
\hline$\% 0 / 05$ & $\% 0 / 04$ & $\% 0 / 03$ & $\% 0 / 02$ & $0 \%$ & Silver Nanoparticles & \\
\hline $0 / 001$ & $0 / 001$ & $0 / 001$ & $0 / 001$ & & $\%$ & 0 \\
& & & & & & \\
\hline $0 / 001$ & $0 / 001$ & $0 / 001$ & & & $\%$ & $0 / 02$ \\
\hline $0 / 001$ & $0 / 001$ & & & & $\%$ & $0 / 03$ \\
\hline $0 / 144$ & & & & & $\%$ & $0 / 04$ \\
\hline
\end{tabular}

Table 2 . Post hoc test Comparison of the average number of bacteria and optical density of wells containing composite with different percentages of silver nanoparticles at hour 3

\begin{tabular}{|l|l|l|l|l|l|}
\hline$\% 0 / 05$ & $\% 0 / 04$ & $\% 0 / 03$ & $\% 0 / 02$ & $0 \%$ & $\begin{array}{l}\text { Silver } \\
\text { nanoparticles }\end{array}$ \\
\hline $0 / 001$ & $0 / 001$ & $0 / 001$ & $0 / 001$ & & $\% 0$ \\
\hline $0 / 657$ & $0 / 378$ & $0 / 001$ & & & $\% 0 / 02$ \\
\hline $0 / 004$ & $0 / 001$ & & & & $\% 0 / 03$ \\
\hline $0 / 657$ & & & & & $\% 0 / 04$ \\
\hline
\end{tabular}

Table 3 . Post hoc test Comparison of the average number of bacteria and optical density of wells containing composite with different percentages of silver nanoparticles at hour 24 
control group. The present study also points to the existence of such a phenomenon. In their study, Durner et al. added silver nanoparticles of percentages $0.125,0.225,0.05,0.1,0.03$, and 0.4 , to composites to investigate the amount of monomer release or washing and other compounds. The rate of washes in samples with 0.1 and $0.3 \%$ weight were significantly higher than the other groups, and it was proved that nanoparticles in these percentages affect the polymerization process of dental materials [17]. By increasing the release of materials from polymerized composites, the adaptability of silver containing materials decreases; hence, we used nanoparticles in lower weight percentages for the present study [15]. The study of Lee et al. showed that the binding of streptococci to the resin adhesives was significantly less than for noncomposite types such as resin-modified glass ionomer, due to this polarization phenomenon and the surface properties of glass ionomer modified with resin, which has a more rigid surface than conventional composites [18]. Resin groups containing silver nanoparticles were rigorously reported to be the least affected by the effect of inhibiting silver nanoparticles [19]. In this study, the antibacterial properties of the resins are due to direct contact with bacteria. It is argued that the silver nanoparticles are not released from the composite mass [3], and therefore are not effective against adjacent bacteria in the liquid medium. This, as an issue in maintaining mechanical and bond strength of the composites is very useful, because it prevents the formation of bubbles within the composite masses and, as a result, prevents weaknesses in the composite. In other studies, the antibacterial effects of additives in composites have been investigated by the turbidity method [20]. In our study, there was a significant difference in the bacterial growth rate. The mechanism by which silver nanoparticles exhibit their antibacterial properties state that silver ions react with living bacterial enzymes and inactivate them, causing bacteria to lose their ability to replicate and then die [14]. In the present study, the growth process of bacteria at 3,24, and 48 hours at concentrations of two-hundredths of weight percent is not significant, while in the four- and fivehundredth concentrations, this trend decreases. This means that $100 \%$ inhibition of bacterial growth does not occur, and hence, they continue to proliferate. On the other hand, in higher concentrations, due to the rapid and effective effect of the silver nanoparticles, this growth preclusion is quite clear. However, at a concentration of three-hundredths of a percent, this process initially decreased at 24 hours, in comparison with three hours, and then increased. Ghasempour et al. [20] stated that it's because of bacterial log phase that the number of bacterial cells doubles at a constant, exponential rate. Another important advantage of silver is that it does not create bacterial resistance, which should be between 1-10 nm for direct contact of nanoparticles with bacteria. In this study, the average size of nanoparticles was $40 \mathrm{~nm}$, which had the optimum antibacterial effect [22].

\section{Conclusion}

In this study, all the groups containing silver nanoparticles had antibacterial effects which were statistically significant in all groups and minimum bactericidal concentration was $0 / 02$ $\%$ ww of Nano silver. 


\section{Reference}

1. Albandar J, Brunelle J, Kingman A (1997) Destructive periodontal disease in adults 30 years of age and older in the United States, 1988-1994. Journal of periodontology 70: 1329.

2. MJÖR IA (2005) Clinical diagnosis of recurrent caries. The Journal of the American Dental Association. 136:1426-33.

3. Stencel R, Kasperski J, Pakieła W, Mertas A, Bobela E, et al. (2018) Properties of Experimental Dental Composites Containing Antibacterial Silver-Releasing Filler. Materials11:1031.

4. Shafiei F, Ashnagar A, Ghavami-Lahiji M, Najafi F, Marashi SMA (2018) Evaluation of Antibacterial Properties of Dental Adhesives Containing Metal Nanoparticles. Journal of Dental Biomaterials5:510-519.

5.Mjör IA, Toffentti F (2003) Secondary caries: A literature review with case reports. Quintessence International. 31.

6.Puppin-Rontani R, Mattos-Graner OR, Correr-Sobrinho L, Garcia-Godoy F (2009) Analyses of biofilms accumulated on dental restorative materials. American journal of dentistry22:131-136.

7.Neves PBAd, Agnelli JAM, Kurachi C, Souza CWOd (2014) Addition of silver nanoparticles to composite resin: effect on physical and bactericidal properties in vitro. Brazilian dental journal25:141-145.

8.Imazato S (2009) Bio-active restorative materials with antibacterial effects: new dimension of innovation in restorative dentistry. Dental materials journal 28:11-19.

9.Elsaka SE, Hamouda IM, Swain MV (2011) Titanium dioxide nanoparticles addition to a conventional glassionomer restorative: influence on physical and antibacterial properties. Journal of dentistry39:589-598.

10.Uchihara T (2007) Silver diagnosis in neuropathology: principles, practice and revised interpretation. Acta neuropathologica113:483-499.

11.Kim JS, Kuk E, Yu KN, Kim J-H, et al. (2007) Antimicrobial effects of silver nanoparticles. Nanomedicine: Nanotechnology, Biology and Medicine 3: 95-101.

12.Sadeghi B, Garmaroudi FS, Hashemi M, Nezhad H, Nasrollahi A, et al. (2012) Comparison of the anti-bacterial activity on the nanosilver shapes: nanoparticles, nanorods and nanoplates. Advanced Powder Technology23:22-26.

13.Azarsina M, Kasraei S, Yousefi-Mashouf R, Dehghani N, Shirinzad M (2013) The antibacterial properties of composite resin containing nanosilver against Streptococcus mutans and Lactobacillus. The journal of contemporary dental practice 14:1014.
14.Cheng L, Weir MD, Xu HH, Antonucci JM,et al. (2012) Antibacterial amorphous calcium phosphate nanocomposites with a quaternary ammonium dimethacrylate and silver nanoparticles. Dental Materials 28:561-572.

15.Nam K-Y (2011) In vitro antimicrobial effect of the tissue conditioner containing silver nanoparticles. The journal of advanced prosthodontics. 3:20-24.

16.Sondi I, Salopek-Sondi B (2004) Silver nanoparticles as antimicrobial agent: a case study on E. coli as a model for Gram-negative bacteria. Journal of colloid and interface science275:177-182.

17.Durner J, Stojanovic M, Urcan E, Hickel R, Reichl F-X (2011) Influence of silver nano-particles on monomer elution from light-cured composites. dental materials27:631-636.

18.Lee S-P, Lee S-J, Lim B-S, Ahn S-J (2009) Surface characteristics of orthodontic materials and their effects on adhesion of mutans streptococci. The Angle Orthodontist79:353-360.

19.Degrazia FW, Leitune VCB, Garcia IM, Arthur RA, Samuel SMW, Collares FM (2016) Effect of silver nanoparticles on the physicochemical and antimicrobial properties of an orthodontic adhesive. Journal of Applied Oral Science24:404-410.

20.Hojati ST, Alaghemand H, Hamze F, Babaki FA, RajabNia R, et al. (2013) Antibacterial, physical and mechanical properties of flowable resin composites containing zinc oxide nanoparticles. Dental materials. 29:495-505.

21.Ghasempour M, Molana Z, Alaghemand H, Beirami A, Bijani A, et al. (2014) Anti-Streptococcus mutansnon-fluoride and fluoride containing sealants after adding nano-silver particles. Journal of Dental Medicine. 27: 16-23.

22. Haghgoo R, Saderi H, Eskandari M, Haghshenas H, Rezvani M (2014) Evaluation of the antimicrobial effect of conventional and nanosilver-containing varnishes on oral streptococci. Journal of Dentistry15:57.

Submit your manuscript to a JScholar journal and benefit from:

ฯ Convenient online submission

ฯ Rigorous peer review

ฯ Immediate publication on acceptance

ๆ Open access: articles freely available online

q High visibility within the field

I Better discount for your subsequent articles Submit your manuscript at http://www.jscholaronline.org/submit-manuscript.php 